\title{
Dexrazoxane exacerbates doxorubicin-induced testicular toxicity
}

\author{
Mattan Levi, Moran Tzabari, Naphtali Savion ${ }^{1,3}$, Salomon M Stemmer ${ }^{2,3}$, Ruth Shalgi \\ and Irit Ben-Aharon ${ }^{2,3, *}$ \\ Department of Cell and Developmental Biology, Sackler Faculty of Medicine, Tel Aviv University, Ramat Aviv, \\ Tel Aviv 69978, Israel, ' The Goldschleger Eye Research Institute, Sheba Medical Center, Tel Hashomer 52621, Israel, \\ ${ }^{2}$ Institute of Oncology, Davidoff Center, Rabin Medical Center, Beilinson Campus, 39 Jabotinski Street, Petah-Tiqva \\ 49100, Israel and ${ }^{3}$ Sackler Faculty of Medicine, Tel Aviv University, Ramat Aviv, Tel Aviv 69978, Israel
}

Correspondence should be addressed to I Ben-Aharon; Email: iritbenaharon@gmail.com

*(R Shalgi and I Ben-Aharon contributed equally to this work)

\begin{abstract}
Infertility induced by anti-cancer treatments pose a major concern for cancer survivors. Doxorubicin (DXR) has been previously shown to exert toxic effects on the testicular germinal epithelium. Based upon the cardioprotective traits of dexrazoxane (DEX), we studied its potential effect in reducing DXR-induced testicular toxicity. Male mice were injected with $5 \mathrm{mg} / \mathrm{kg} \mathrm{DXR,} 100 \mathrm{mg} / \mathrm{kg} \mathrm{DEX,} \mathrm{combination} \mathrm{of}$ both or saline (control) and sacrificed either 1, 3 or 6 months later. Testes were excised and further processed. Glutathione and apoptosis assays were performed to determine oxidative stress. Immunohistochemistry and confocal microscopy were used to study the effects of the drugs on testicular histology and on spermatogonial reserve. DXR and the combined treatment induced a striking decline in testicular weight. DEX prevented DXR-induced oxidative stress, but enhanced DXR-induced apoptosis within the testes. Furthermore, the combined treatment depleted the spermatogonial reserve after 1 month, with impaired recovery at 3 and 6 months post-treatment. This resulted in compromised sperm parameters, testicular and epididymal weights as well as significantly reduced sperm motility, all of which were more severe than those observed in DXR-treated mice. The activity of DEX in the testis may differ from its activity in cardiomyocytes. Adding DEX to DXR exacerbates DXR-induced testicular toxicity.

Reproduction (2015) $\mathbf{1 5 0} 357-366$
\end{abstract}

\section{Introduction}

Seminal advances in anti-cancer therapy as well as supportive care strategies result in improved survival rates, reaching $80 \%$ in the pediatric population (Ward et al. 2014). The growing numbers of young cancer survivors shed an ancillary focus on preservation of an optimum quality of life after anti-cancer treatments. The Childhood Cancer Survivor Study indicated that male survivors were substantially less likely to attain a pregnancy (hazard ratio $0.56,95 \% \mathrm{Cl} 0.49-0.63$ ) compared to their siblings (Green et al. 2010). Nevertheless, although male infertility is one of the major lateterm concerns of anti-cancer treatments during childhood and adolescence (Brougham et al. 2003, Wallace 2011), the mechanism of chemotherapy-induced testicular toxicity remains to be elucidated. Studies have demonstrated that several classes of chemotherapy alter spermatogenesis in the pre-pubertal and early pubertal testis (Masala et al. 1997, Thomson et al. 2002, Longhi et al. 2003).
Doxorubicin (DXR), an anthracycline that is a cornerstone of many chemotherapeutic regimens, is used for treating a wide spectrum of malignancies including both hematological and solid tumors. DXR has been previously studied for its deleterious effect on the gonadal epithelium in rodents, where it was shown to cause chromosome aberrations in spermatogonial cells (Au \& Hsu 1980, Abraham \& Fränz 1983), inhibition of DNA synthesis and induction of apoptosis (Brinkworth et al. 1995, Blanco-Rodríguez \& MartínezGarcía 1996, Shinoda et al. 1999, Hou et al. 2005). DXR has been shown to disrupt sperm maturation, reduce epididymal sperm concentration as well as alter spermatogonial DNA and sperm morphology (Meistrich et al. 1990). One of the ways that DXR exerts its toxic effect on the testis is via oxidative stress, affecting spermatogenesis and sperm function (Ateşşahin et al. 2006, Tanigaki et al. 2013). Oxidative stress by DXR was widely established in other tissues and is probably one of the most accepted pathways of cardiac toxicity (Quiles et al. 2002, Wolf \& Baynes 2006, Octavia et al. 2012). 
Dexrazoxane (DEX; ICRF-187) is a chelator of intracellular free iron that has been found to effectively reduce the formation of oxygen free radicals by DXR (Keizer et al. 1990). DEX was approved by the US Food and Drug Administration (FDA) as a cardioprotective agent in conjunction with DXR, though its mechanism of action is not yet fully understood. DEX was also approved as an antidote for alleviating tissue damage due to accidental anthracycline skin extravasation (Grauslund et al. 2007). DEX has been shown to reduce DXR-induced oxidative stress processes and apoptosis in cardiomyocytes. Preclinical and clinical studies conferred a protective role for DEX on cardiac function devoid of any effect on the rate of response to chemotherapy or on overall survival of the treated patient (Cvetković \& Scott 2005, Jirkovský et al. 2013). DEX, which was originally developed as an antitumor agent, belongs to a class of molecules, bis (2,6-dioxopiperazines), known to function as topoisomerase II (Topoll) catalytic inhibitors and differs from the classical anti-cancer agents such as anthracyclins (Andoh \& Ishida 1998). Nevertheless, the clinical use of DEX is still limited due to concerns regarding its potential for rescuing tumor cells from the therapeutic effect of DXR (Sepe et al. 2010).

Attempts have been made to evaluate the role of various cytoprotectants in reducing DXR-induced testicular toxicity, based upon their role in apoptotic and oxidative stress pathways. These include amifostin, lycopene and other anti-oxidants with conflicting evidence as for their benefit (Hou et al. 2005, Yeh et al. 2007, 2009, Vendramini et al. 2010). Due to the promising role of DEX in reducing DXR-induced cardiac toxicity, our aim was to evaluate its role in reducing DXR-induced testicular toxicity by assessing morphological and biochemical measurements following in vivo administration of DXR with or without DEX.

\section{Materials and methods}

\section{Animals}

Adult ICR male mice (8 weeks old; Harlan Laboratories, Jerusalem, Israel) were housed in air conditioned, light controlled animal facilities of the Sackler Faculty of Medicine in Tel-Aviv University. Animal care and experiments were in accordance with institutional guidelines and were approved by the Institutional Animal Care and Use Committee, Sackler Faculty of Medicine, Tel-Aviv University, ID TAU-R 100106.

\section{Drugs administration and experimental design}

Male mice were weighed and injected intraperitoneally (IP) with DEX (100 mg/kg, Cardioxane; Taro, Haifa, Israel), DXR ( $5 \mathrm{mg} / \mathrm{kg}$, Adriamycin; Teva, Petach Tikva, Israel), both DEX and DXR or saline (control). Mice were re-weighed and sacrificed 1 ( $7,10,9$ and 15 mice respectively), 3 (8, 10, 10 and 12 mice respectively) or 6 months later $(6,8,7$ and 8 mice respectively). DXR chosen dose was similar to the dose used in our female gonadal toxicity study (Ben-Aharon et al. 2010). DEX chosen dose was calculated according to the dose used in humans (USFDA 2005). Mice epididymides were excised, weighed and processed. Cauda epididymides were punctured and sperm were allowed to swim into pre-warmed $\left(37^{\circ} \mathrm{C}\right) \mathrm{M} 2$ medium (M-7167; Sigma) in a $35 \mathrm{~mm}$ petri dish. Sperm motility and progressive motility were assessed $30 \mathrm{~min}$ later by a Makler counting chamber (Sefi Medical Instruments, Haifa, Israel) according to manufacturer's instructions.

\section{Determination of total and oxidized glutathione}

Testes of mice were excised 1 month after treatment, lysed in $10 \mathrm{mM} \mathrm{HCl}$ followed by repeated (×3) freezing and thawing cycles. Proteins were precipitated by $10 \%$ sulfosalicylic acid (SSA), centrifuged $(10000 \mathrm{~g})$, lysed in $0.5 \mathrm{~N} \mathrm{NaOH}$ and quantified by the Lowry protein assay (Lowry et al. 1951). Supernatants total glutathione (reduced GSH and oxidized GSH, GSSG) was determined by the Anderson recycling method (Horev-Azaria et al. 2009).

\section{Western blot analysis}

Testes were excised 1 month after treatment, lysed and their proteins (normalized according to protein content using Bradford quantification assay; Bradford 1976) were separated by $10 \%$ sodium dodecyl sulfate polyacrylamide gel electrophoresis (SDS-PAGE; Bio-Rad) in a Hoefer Mighty small chamber (Amersham). Separated proteins were transferred onto nitrocellulose membranes (Whatman $\mathrm{GmbH}$, Freiburg, Germany) in a mini tank transfer unit (TE 22, Amersham, UK). Approximate molecular masses were determined by comparison with the migration of pre-stained protein standards (BioRad). Blots were blocked for an hour in TBST (10 mM Tris- $\mathrm{HCl}$, $\mathrm{pH}=8.0,150 \mathrm{mM} \mathrm{NaCl}$ and $0.05 \%$ Tween 20) containing $5 \%$ skim-milk (ALBA, Denver, CO, USA) or 2\% BSA (Biological Industries, Kibbutz Beit Haemek, Israel) followed by over-night incubation at $4{ }^{\circ} \mathrm{C}$ with either rabbit polyclonal anti Bax (1:200; Santa Cruz Biotechnology) or mouse monoclonal anti phosphorylated-P38 (Ph-P38) and rabbit polyclonal anti generalP38 (Gen-P38; 1:10 000; Sigma) antibodies. Blots were washed three times in TBST and incubated for an hour at room temperature with goat anti-rabbit or anti-mouse secondary antibodies conjugated to horseradish peroxidase (1:10 000; Jackson ImmunoResearch Laboratories, West Grove, PA, USA). Immunoreactive bands were visualized by ECL (Thermo Scientific, Rockford, IL, USA) according to manufacturer's guidelines. Intensity of the protein bands was quantified by the freely available Image-J Software (NIH, Bethesda, MD, USA).

\section{Immunohistochemistry and confocal microscopy}

Testes of mice were excised 1, 3 or 6 months after treatment and fixed in either Bouin solution (Stat Lab, McKinney, TX, USA) or 4\%; paraformaldehyde (Merck, Darmstadt, Germany). Tissues were embedded in paraffin, sectioned $(8 \mu \mathrm{m})$ and mounted on Superfrost/Plus slides (Daigger and Co. Wheeling, IL, USA). The Bouin-fixed samples were stained with hematoxylin and eosin. Paraformaldehyde-fixed samples, 
destined for immunohistochemistry, were deparaffinized, microwaved for $3 \mathrm{~min}$ in citrate-based antigen unmasking solution (H-3300; Vector Laboratories, Burlingame, CA, USA), incubated with PBSTg (0.2\% Tween-20, $0.2 \%$ gelatin in PBS; $1 \mathrm{~h}$ ), rinsed in PBS, blocked in blocking solution (927B; Cell Marque, Rocklin, CA, USA; $10 \mathrm{~min}$ ) and incubated overnight at $4{ }^{\circ} \mathrm{C}$ with primary antibodies: rabbit anti-proliferating cell nuclear antigen (PCNA; Santa Cruz), goat anti-deleted in azoospermia-like (DAZL; Novus Biologicals, Littleton, CO, USA), goat anti-GATA-4 (Santa Cruz) and/or mouse antipromyelocytic leukemia zinc-finger (PLZF; Santa Cruz). We used the following secondary fluorescent antibodies (Jackson ImmunoResearch Laboratories): Cy2-conjugated donkey antirabbit for PCNA-staining, Cy3-conjugated donkey anti-goat for DAZL-staining, Cy2-conjugated donkey anti-goat for GATA4-staining and Cy3-conjugated donkey anti-mouse for PLZF-

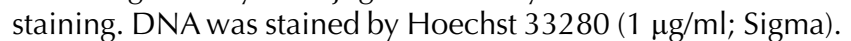
Sections were rinsed in PBS $(\times 3)$, mounted with mowiol (Sigma) and photographed by Zeiss-LSM-510 confocal laserscanning microscope (CLSM; Carl Zeiss Microlmaging; PlanNeofluar $25 \times$ objective). Staining with secondary antibodies only (Supplementary Fig. 1a and b, see section on supplementary data given at the end of this article) served as negative control for the photomultiplier offset calibration in fluorescent images, whereas, Ki-67 staining of tonsil tissue (Supplementary Fig. 1c) served as positive control for DIC images.

At least 30 randomly-selected images of seminiferous tubules from each experimental group were photographed (Zeiss-LSM-510 confocal laser-scanning microscope with a Plan-Neofluar $25 \times$ objective). All the cells in each field of view were counted and the average ratio of the total number of TUNEL, DAZL and PLZF-positive cells per Sertoli cell was assessed.

\section{Apoptosis evaluation}

DNA fragmentation was examined in situ on paraffinembedded testicular sections by terminal transferase-mediated dUTP nick-end labeling (TUNEL; DeadEnd fluorometric TUNEL system, Promega) according to manufacturer's instructions. Sections exposed for $10 \mathrm{~min}$ to DNase I $(6 \mathrm{units} / \mathrm{ml}$; Invitrogen) served as positive controls.

\section{Statistical analysis}

The measured parameters of male mice injected IP with saline (control), DEX $(100 \mathrm{mg} / \mathrm{kg}), \mathrm{DXR}(5 \mathrm{mg} / \mathrm{kg})$ or a combination of DEX and DXR and sacrificed 1, 3 or 6 months later were analyzed statistically. Each experiment was repeated at least three times. SPSS 10.0 Software was used for statistical analysis. Independent, two-sample $t$-test for unequal sample sizes and unequal variances with significance of $P<0.05$, was employed for assessing the differences among the experimental groups in body, testicular and epididymal weights as well as in spermatozoa motility and progressive motility. For western blotting experiments, protein quantification was performed using the Image-J Software. Differences in the intensity of protein bands of Bax, Ph-P38 and Gen-P38 were assessed using the two-way ANOVA test with significance of $P<0.05$.

\section{Results \\ DEX reduces DXR-induced oxidative stress but enhances testicular apoptosis}

In an attempt to assess the role of DEX as a testicular antioxidant, we performed a glutathione assay and found a decrease of more than $50 \%$ in glutathione level in testes of DXR treated mice, 1 month after treatment (Fig. 1A), implying that oxidative stress may mediate DXR-induced testicular toxicity. We chose the time point of 1 month because the length of mouse spermatogenic cycle is 35 days (Oakberg 1957). Furthermore, we showed that the DXR-induced activation of Ph-P38, a marker for oxidative stress, was prevented completely by DEX administration (Fig. 1B), indicating that in testes, as in cardiomyocytes, DEX reduced the magnitude of oxidative stress exerted by DXR. Bax, a pro-apoptotic factor known to regulate the apoptotic response, was highly expressed in mice testes 1 month after administration of DXR. The level of Bax after administration of both agents was significantly higher than its level after administration of saline or of DXR alone (Fig. 1C). Furthermore, the results of the TUNEL experiment indicate an increase of
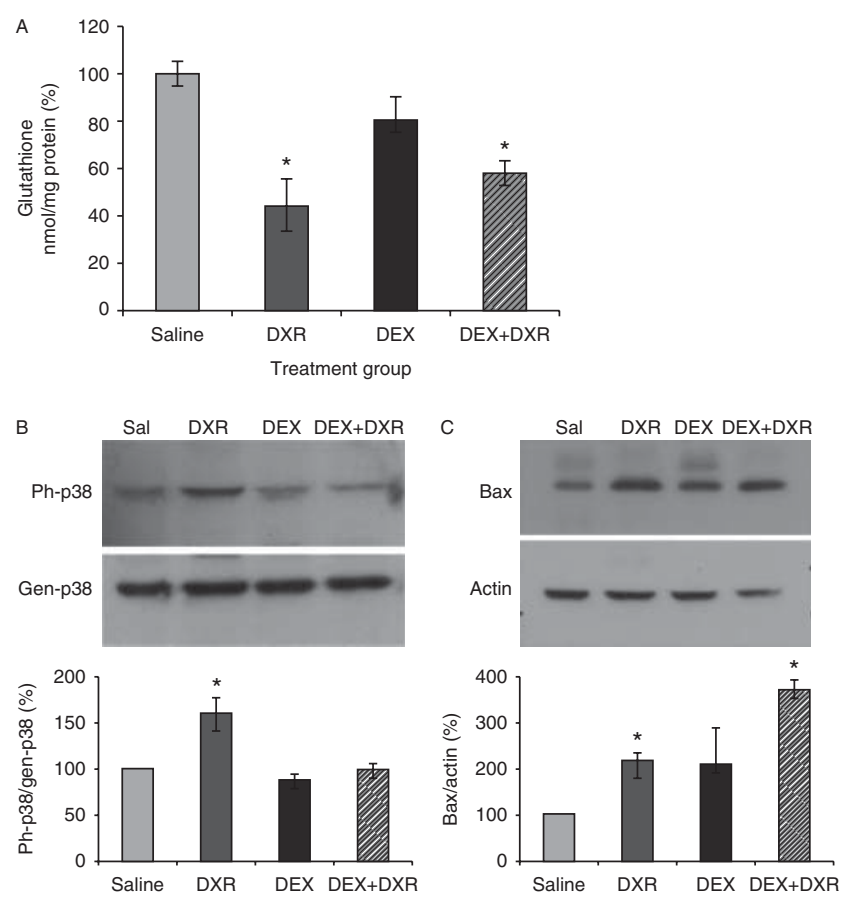

Figure 1 DEX reduced DXR-induced oxidative stress but enhanced testicular apoptosis. Male mice were injected with saline, DXR ( $5 \mathrm{mg} / \mathrm{kg})$, DEX (100 mg/kg) or DEX and DXR. Their testes were excised 1 month later, lysed and either incubated with $10 \%$ sulfosalicylic acid for glutathione assay (A) or resolved by SDS-PAGE and immunoblotted with anti Ph-P38 (B) or anti Bax (C); re-probed with antibodies directed against Gen-P38 or actin respectively. Graphic presentations of the intensity of the P38 or Bax protein bands, quantified by the Image-J Software, appear below the protein bands. $\left({ }^{*}\right)$ - significantly different from control value $(P<0.05)$. Each bar represents at least five mice. 
apoptosis 1 month after treatment with DXR alone or with DXR and DEX (Fig. 2A).

\section{The effect of DEX and DXR on testicular and epididymal weights and on sperm motility}

We examined the short (1 month) and long term (3 or 1 months after drug injection) effects of DEX and DXR on body, testicular and epididymal weight, as well as on sperm motility. DEX alone had no significant effect on body weight (Supplementary Fig. 2, see section on supplementary data given at the end of this article). Males injected with DXR, regardless of DEX, gained less weight at the 1st month compared to control mice injected with saline $(P<0.05)$. Total weight-gain, 3 and 6 months after the injection, was the same in all groups (Supplementary Fig. 2). One month after injection the testicular weight of DEX-injected mice was significantly lower than that of testes of control mice at 1 month (Fig. 3A; $P<0.05$ ), but it was restored after 3 months. Testicular weight of DXR-injected mice was also decreased 1 month after injection. Although body weight gain was restored 3 and 6 months after injection, testicular weight was still significantly lower than that of
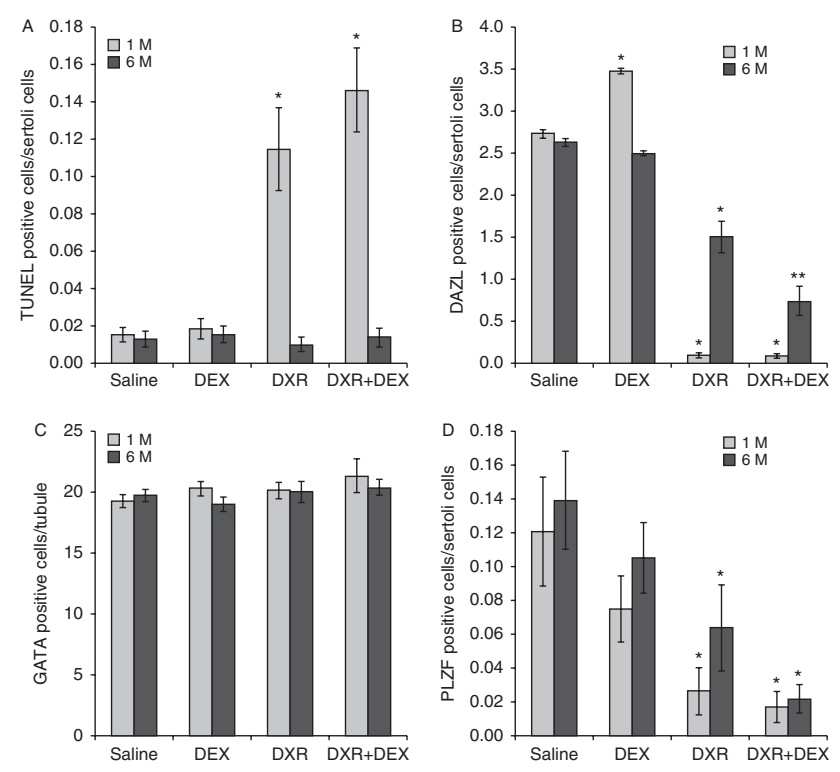

Figure 2 Quantification of spermatogenic milieu. Testes excised from adult male mice 1 or 6 months after injection of saline, DXR $(5 \mathrm{mg} / \mathrm{kg})$, DEX $(100 \mathrm{mg} / \mathrm{kg})$ or both (DXR + DEX). TUNEL staining was used for apoptosis assessment (A). DAZL staining was used for spermatocytes assessment (B). GATA-4 staining was used for Sertoli cells assessment (C). PLZF staining was used for undifferentiated spermatogonia assessment (D). At least 30 transverse sections of seminiferous tubules were selected randomly in each experimental group, photographed by Zeiss-LSM-510 confocal laser-scanning microscope with Plan-Neofluar $25 \times$ objective and the average number of TUNEL, DAZL and PLZFpositive cells per Sertoli cells in the field of view was assessed. Each bar is mean \pm S.E.M. $\left({ }^{*}\right)$ - significantly different from control value (saline; $P<0.05)$. $\left({ }^{* *}\right)$ - significantly different from control and DXR values $(P<0.05)$.
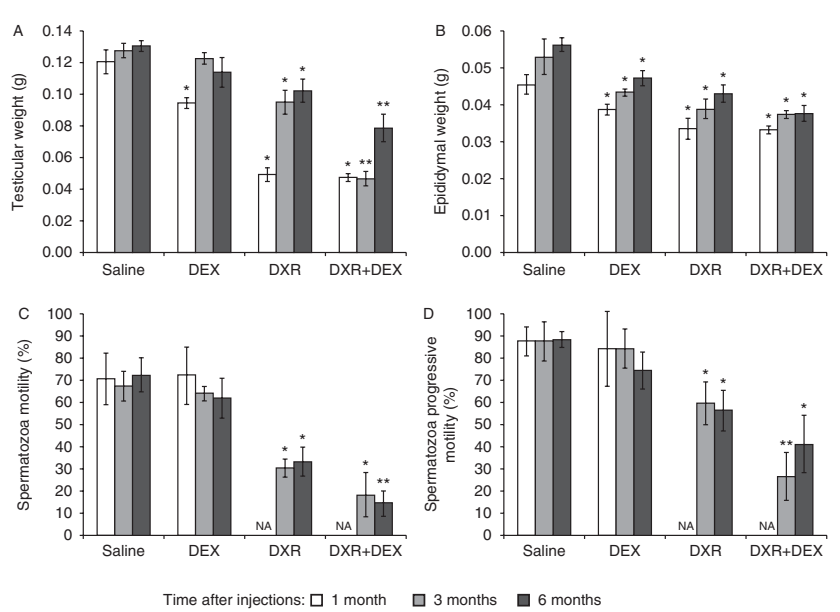

Figure 3 Effect of DEX on testicular function. Male mice (8 weeks old) were injected with saline, DEX (100 mg/kg), DXR $(5 \mathrm{mg} / \mathrm{kg})$, or DEX and DXR. Testicular weight (A), epididymal weight (B), sperm motility (C) and sperm progressive motility (D) were measured when mice were sacrificed: 1 month (7, 10, 9 and 15 mice respectively), 3 months $(8,10,10$ and 12 mice respectively) or 6 months $(6,8,7$ and 8 mice respectively) after drug administration. Each bar is mean \pm s.E.M. $(*)$ - significantly different from control value (saline; $P<0.05$ ). $\left({ }^{* *}\right)$ - significantly different from control and DXR values $(P<0.05)$. NA - not assessed due to azoospermia.

control mice $(P<0.05)$. Surprisingly, the long term ( 3 and 6 months) recovery of testicular weight in mice injected with DEX and DXR was lower than that of DXR-only injected mice $(P<0.05)$. Furthermore, we assessed epididymal weight as a possible indicator of sperm amount and found that DEX, DXR and the combined treatment, all caused an irreversible decrease of epididymis weight $(P<0.05$; Fig. $3 \mathrm{~B})$. We assessed the epididymal sperm as well and found that male mice became azoospermic 1 month after DXR treatment with or without DEX; virtually no sperm was found in the epididymis. Spermatozoa were observed in the epididymis 3 and 6 months after DXR-injection. However, their motility (Fig. 3C) and progressive motility (Fig. 3D), two important functional properties, were impaired $(P<0.05)$. Combined DEX and DXR treatment caused an even more severe reduction of spermatozoa motility and progressive motility after 3 months, compared to that of mice injected with DXR alone $(P<0.05)$.

\section{DEX alters spermatogenic milieu and induces spermatocytes proliferation}

Testicular histological sections were analyzed to evaluate specific structural changes and damage caused by in vivo exposure to the various treatments. One month after saline injection (control; Fig. 4A, Supplementary Fig. 3a, see section on supplementary data given at the end of this article), the majority of seminiferous tubules contained long spermatids, whereas 1 month after DEX injection the majority of seminiferous tubules were devoid of long 

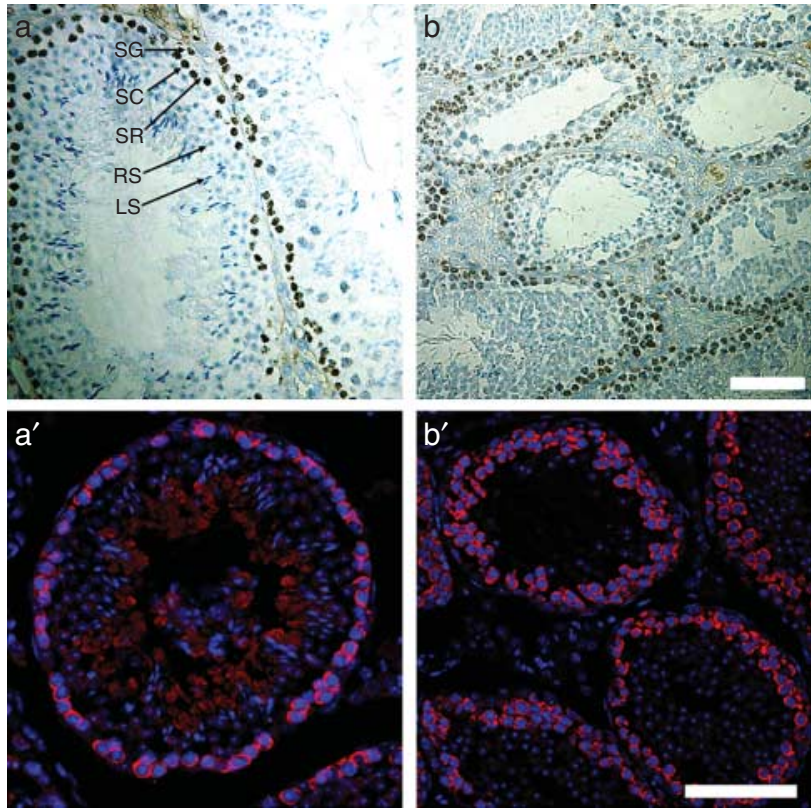

Figure 4 Increase of meiotic-active pachytene spermatocytes 1 month after DEX administration. Testes excised from adult male mice 1 month after injection of saline $\left(a\right.$ and $\left.\mathrm{a}^{\prime}\right)$ or DEX $\left(100 \mathrm{mg} / \mathrm{kg}\right.$; $b$ and $\left.\mathrm{b}^{\prime}\right)$. Representative DIC images ( $a$ and $b$ ) of testes stained for Ki-67 (proliferating cells; brown) and hematoxylin (blue). Representative CLSM images $\left(\mathrm{a}^{\prime}\right.$ and $\left.\mathrm{b}^{\prime}\right)$ of testes stained for DAZL (spermatogonia as well as preleptotene and pachytene spermatocytes; red) and Hoechst 33280 (DNA; blue). Primary and secondary antibodies were diluted 1:200. SG, spermatogonium; SC, spermatocyte; SR, Sertoli cell; $\mathrm{RS}$, round spermatid; LS, long spermatid; Bars $=100 \mu \mathrm{m}$.

spermatids and contained mostly spermatocytes (Fig. 4B, Supplementary Fig. 3b). We performed differential staining with: Ki-67 to detect proliferation (spermatogonia are stained darker than pachytene spermatocytes), PCNA to detect proliferating cells and cells during DNArepairing, and DAZL to detect spermatogonia, preleptotene and pachytene spermatocytes (Fig. 4B and B', Supplementary Fig. $3 b^{\prime}$ and $b^{\prime \prime}$ ). Our results show an increase in the number of pachytene-stage spermatocytes, 1 month after DEX administration (Fig. 2B) compared to control. The effect of DEX on testicular reserve and on Sertoli cells was assessed by two immunohistochemical biomarkers: PLZF, which is expressed specifically in A-single (As), A-pair (Ap) and A-aligned (Al) undifferentiated spermatogonia (Phillips et al. 2010) and GATA-4, a Sertoli-cells marker (McCoard et al. 2001). Our data show that 1 month after DEX administration the number of Sertoli cells and of undifferentiated spermatogonia (Supplementary Fig. 3b"'I) was similar to that of control saline-administered mice (Supplementary Fig. 3a'"', Fig. 2C and D).

\section{DEX exacerbates DXR detrimental effect on the testis}

We employed immunohistochemistry to assess the short term (1 month after drug administration) testicular effect of DXR and of the combined treatment. Treatment with DXR, whether administered solely (Fig. 5B, Supplementary Fig. 3C, see section on supplementary data given at the end of this article) or with DEX (Fig. 5C, Supplementary Fig. 3D), caused a detrimental effect on testicular histology, manifested by obliteration of the typical morphology and appearance of vacuoles in the seminiferous tubules. However, when compared to control (Fig. 5A), and even to DXR alone (Fig. 5B and Fig. 6; Supplementary Fig. $3 c^{\prime}$ ), fewer seminiferous tubules containing Ki-67-positive spermatogonia were observed in the testes of mice receiving the combined DEX-DXR treatment (Fig. 5C and Fig. 6, Supplementary Fig. $3 d^{\prime}$ ). Significantly fewer DAZL-positive spermatogonia and spermatocytes remained after treatment with DXR, whether administered solely (Fig. 2B, Fig. 5b') or with DEX (Fig. 2B, Fig. 5c'). GATA-4 staining for Sertoli cells indicated survival of these cells and showed no significant effect on the number of Sertoli cells, 1 month after administration of DXR (Fig. 2C and Fig. 5b") or of the combined treatment (Fig. $2 \mathrm{C}$ and Fig. $5 \mathrm{C}^{\prime \prime}$ ). The number of undifferentiated spermatogonia As/Ap/Al in testes of mice treated with DXR alone or with the combined treatment was significantly lower than in
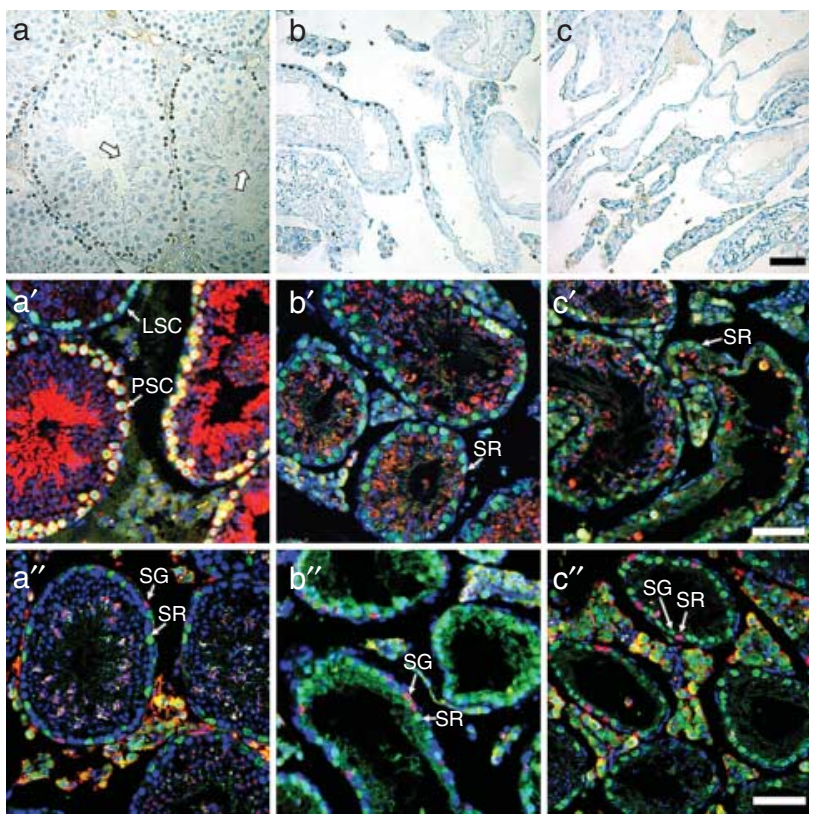

Figure 5 Testicular characterization 1 month after DXR or DEX and DXR administration. Testes excised from adult male mice 1 month after injection of saline $\left(\mathrm{a}, \mathrm{a}^{\prime}\right.$ and $\left.\mathrm{a}^{\prime \prime}\right)$, DXR $\left(5 \mathrm{mg} / \mathrm{kg} ; \mathrm{b}, \mathrm{b}^{\prime}\right.$ and $\left.\mathrm{b}^{\prime \prime}\right)$ or DEX $(100 \mathrm{mg} / \mathrm{kg})$ and DXR (5 mg/kg; c, c ${ }^{\prime}$ and $\left.\mathrm{c}^{\prime \prime}\right)$. Representative DIC images of testes stained for Ki-67 (proliferating cells; brown) and hematoxylin (blue; $a, b$ and c). Representative CLSM images of testes stained for PCNA (green), DAZL (red) and Hoechst 33280 (blue; $a^{\prime}, b^{\prime}$ and '); or GATA-4 (Sertoli cells, green), PLZF (As/Apr/Aal spermatogonia; red) and Hoechst 33280; blue; $a^{\prime \prime} b^{\prime \prime}$ and $\left.c^{\prime \prime}\right)$. Primary and secondary antibodies were diluted 1:200. LPS, leptotene spermatocyte; PSC, pachytene spermatocyte; SG, spermatogonium; SR, Sertoli cell; Bar $=100 \mu \mathrm{m}$. 


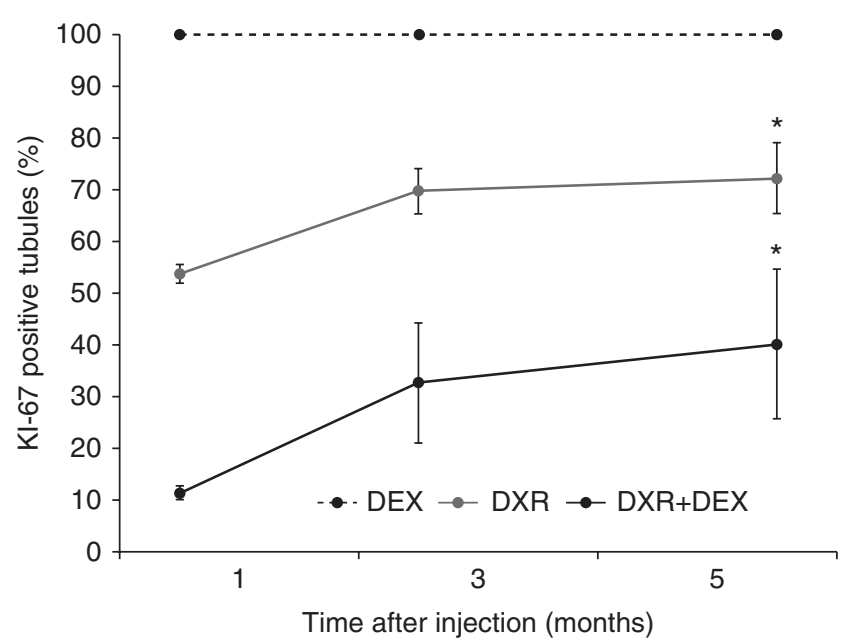

Figure 6 Combined DXR and DEX treatment decreased the number of seminiferous tubules exhibiting proliferation, compared to DXR alone. The average number of seminiferous tubules containing Ki-67-positive cells 1, 3 or 6 months after injection of DEX (100 mg/kg; dashed line), DXR ( $5 \mathrm{mg} / \mathrm{kg}$; gray line) or combined treatment (black line), was quantified as percent of those in testes of saline-injected control mice. At least 70 transverse sections of seminiferous tubules were examined in each group and the average number of seminiferous tubules containing Ki-67-positive cells is calculated. Each point is mean \pm s.E.M. $(*)$ - significantly different from control value (saline; $t$-test; $P<0.05$ ).

testes of control mice, both 1 and 6 months after treatment (Fig. 2D).

The effect of DXR, administered alone or with DEX, was not stage specific. Ablation of germ cells from seminiferous tubules occurred at stages IX-XII and I-VIII by either DXR alone (Supplementary Fig. 3c') or when administered with DEX (Supplementary Fig. $3 d^{\prime}$ ).

\section{Partial testicular recovery from DXR toxicity}

Histological staining, immunohistochemistry and confocal microscopy were used to further study the recovery of the testes from the detrimental effects of DXR and DXR-DEX. The results demonstrate that testicular morphology and cell distribution within the seminiferous tubules of testes of control (Figs 7 and $8 a, a^{\prime}$ and $a^{\prime \prime}$ ) and DEX (Figs 7 and $8 b, b^{\prime}$ and $b^{\prime \prime}$ ) treated mice were similar 3 and 6 months post treatment. The number of spermatocytes affected by DEX alone returned to control values (Fig. 2B), but only partial recovery was observed, 3 and even 6 months post-treatment, in testes of mice treated with DXR, whether administered solely (Figs 7 and $8 \mathrm{c}, \mathrm{c}^{\prime}$ and $\mathrm{c}^{\prime \prime}$ ) or with DEX (Figs 7 and $8 \mathrm{~d}, \mathrm{~d}^{\prime}$ and $\mathrm{d}^{\prime \prime}$ ). Moreover, most of the tubules within the testes of mice treated with DXR recovered and exhibited all types of germ cells, including Ki-67-positive proliferating cells, whereas most of the tubules within the testes of mice treated with a combination of DEX and DXR exhibited a Sertoli-cell-only (SCO) pattern with no Ki-67-positive proliferating cells (Fig. 6, Figs 7 and $8 d^{\prime}$ ).

\section{Discussion}

The rationale behind the use of DEX in an attempt to reduce DXR-induced testicular toxicity was based upon the biochemical traits of DEX, studied mostly in cardiomyocytes, which paved the way to its implementation as a cardioprotectant. Our results in an in-vivo mouse model indicate that co-administration of DEX and DXR does not result in salvaging spermatogenesis from DXR-induced testicular toxicity, but rather exerts a detrimental effect on the testis, which is more pronounced than the effect of DXR itself.

Spermatogenic cells are highly susceptible to DXR, mainly due to their high mitotic activity. Spermatocytes and spermatogonia are considered predisposed to toxic stimuli, more than other components of the testis (Quiles et al. 2002, Hou et al. 2005).

DXR exerts its testicular toxicity by several pathways: it causes acute impairment of testicular vessels that results in alteration of testicular blood flow (Bar-Joseph et al. 2011). DXR has been shown to adversely affect spermatogenesis as well as the quantity and quality of sperm; it exerts its toxicity via oxidative stress pathways (Sikka 1996, Suominen et al. 2003, Hou et al. 2005, Ateşşahin et al. 2006). Previous studies have demonstrated that the level of malondialdehyde (MDA), which derives from lipid peroxidation, rises after exposure to DXR, whereas the level of GSH declines (Quiles et al. 2002, Ateşşahin et al. 2006). Several protectants have been applied to reduce DXR-induced testicular toxicity (Hou et al. 2005); none of them was implemented into clinical practice. Though our results showed that DEX reduced the oxidative stress exerted by DXR within the testis, the oxidative stress may not be the dominant pathway to mediate DXR toxicity, because despite the protective effect of DEX in this cellular pathway the tissue damage was more prominent in mice receiving the combined treatment. This observation indicates a distinctive mechanism of action for DEX in the testis that differs from its effect on cardiomyocytes. Moreover, both DXR and DEX may trigger unique functional cellular pathways in either type of organs.

Oxidative stress has long been widely accepted as the cause of DXR-induced cardiotoxicity, although there is growing evidence for damage caused via other, non-oxidative, mechanisms. The copious cardiac mitochondria play a key role in the mechanism of DXR cardiotoxicity, resulted from vulnerability of the heart to anthracycline-induced oxidative stress. DEX is known to function as Topoll. There are two Topoll isozymes, Topoll $\alpha$ and Topoll $\beta$, in mammalian cells (Wang et al. 1999) that differ in their cellular regulation and distribution. Topoll $\alpha$, which is only expressed in proliferating and tumor cells, plays important roles in cell cycle pathways, such as DNA replication and chromosome condensation/decondensation (Wang et al. 1999). The high efficacy of DXR chemotherapy 

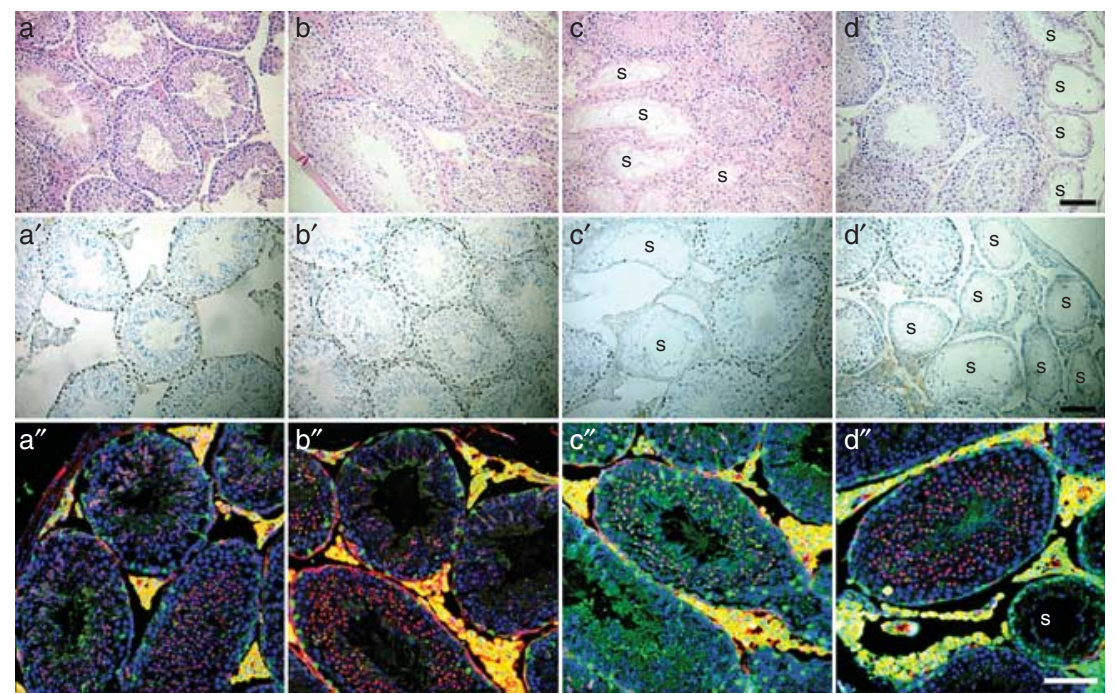

Figure 7 Testicular characterization 3 months after administration of either DXR or DEX and DXR. Testes excised from adult male mice 3 months after injection of saline ( $a, a^{\prime}$ and $\left.a^{\prime \prime}\right)$, DXR $\left(5 \mathrm{mg} / \mathrm{kg}\right.$; b, $\mathrm{b}^{\prime}$ and $\mathrm{b}^{\prime \prime}$ ) or combined treatment $\left(c, c^{\prime}\right.$ and $\left.c^{\prime \prime}\right)$. Representative DIC images of testes stained with hematoxylin (blue) and eosin (pink; $\mathrm{a}, \mathrm{b}, \mathrm{c}$ and d). Representative DIC images of testes stained for Ki-67 (brown) and hematoxylin (blue; $a^{\prime}, b^{\prime}, c^{\prime}$ and $\left.d^{\prime}\right)$. Representative CLSM images of testes stained for GATA-4 (green), PLZF (red) and Hoechst 33280 (DNA; blue; $\mathrm{a}^{\prime \prime}, \mathrm{b}^{\prime \prime}, \mathrm{c}^{\prime \prime}$ and $\mathrm{d}^{\prime \prime}$ ). SG, spermatogonium; SR, Sertoli cell;

SCO, Sertoli-cell-only seminiferous tubule; Bars $=100 \mu \mathrm{m}$ is conferred to abundant expression of Topoll $\alpha$ in cancer cells. Topoll $\beta$, but not Topoll $\alpha$, is expressed in adult heart (Lyu et al. 2007, Vejpongsa \& Yeh 2014). Topoll $\beta$ has been implicated in the mechanism that underlies DXRinduced cardiotoxicity where it targets Topoll $\beta$ in both nuclei and mitochondria of cardiomyocytes. It was demonstrated that DEX reduces DXR-induced DNA damage in the heart through its interference with Topoll $\beta$ (Lyu et al. 2007). Nevertheless, homology modeling studies of human Topoll $\alpha$ and Topoll $\beta$ indicated that the DEX binding sites are the same for both isozymes (Lyu et al. 2007). Being a highly proliferating tissue with abundant mitoses, Topoll $\alpha$ is highly expressed in the testes, mainly in pachytene spermatocytes, and is subjected to testosterone regulation (Bakshi et al. 2001). It has been implied that Topoll may play a role also in the transient double stranded breaks in elongating spermatids (Laberge \& Boissonneault 2005). Furthermore, DXR can induce chromosomal damage in the testis not only via oxidative stress but also by intercalation into DNA and disrupting topo-II-mediated DNA repair. It was also shown that DXR may induce enhanced testicular toxicity in prepubertal rats due to disruption of the supporting Sertoli cells (Brilhante et al. 2012).

To further characterize the effect of DEX on specific compartments of the seminiferous tubules and on spermatogenesis, we employed three immunohistochemical biomarkers: $\mathrm{Ki}-67$, prominently expressed in the nuclei of mitotic spermatogonia and meiotic primary spermatocytes; serves as proliferating index in testis (Lissbrant et al. 2003). PCNA, involved in DNA replication and repair, also prominently expressed in the nuclei of spermatogonia and primary spermatocytes (Chapman \& Wolgemuth 1994, Kamel et al. 1997, Steger et al. 1998, Bar-Shira Maymon et al. 2003). DAZL that stains intermediate and B type spermatogonia as well as preleptotene and pachytene spermatocytes (Saunders et al. 2003). According to our observations DEX caused a

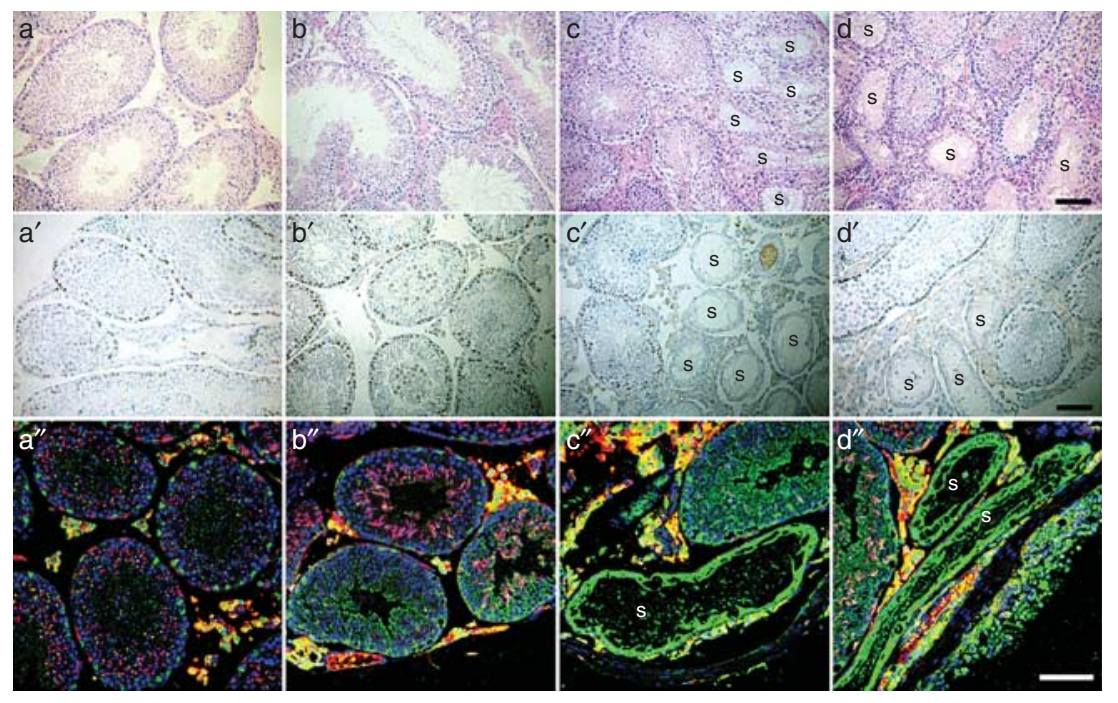

Figure 8 Testicular characterization 6 months after administration of either DXR or DEX and DXR. Testes excised from adult male mice 3 months after injection of saline (a, $a^{\prime}$ and $\left.a^{\prime \prime}\right)$, DXR $\left(5 \mathrm{mg} / \mathrm{kg} ; \mathrm{b}, \mathrm{b}^{\prime}\right.$ and $\left.\mathrm{b}^{\prime \prime}\right)$ or combined treatment $\left(c, c^{\prime}\right.$ and $\left.c^{\prime \prime}\right)$. Representative DIC images of testes stained with hematoxylin (blue) and eosin (pink; a, b, c and d). Representative DIC images of testes stained for Ki-67 (brown) and hematoxylin (blue; $a^{\prime}, b^{\prime}, c^{\prime}$ and $d^{\prime}$ ). Representative CLSM images of testes stained for GATA-4 (green), PLZF (red) and Hoechst 33280 (DNA; blue; $a^{\prime \prime}, b^{\prime \prime}, c^{\prime \prime}$ and $d^{\prime \prime}$ ). SG, spermatogonium; SR, Sertoli cell;

SCO, Sertoli-cell-only seminiferous tubule; Bars $=100 \mu \mathrm{m}$. 
transient enhanced expression of Ki-67, PCNA- and DAZL-positive pachytene spermatocytes. Our results imply that DEX facilitates enhanced proliferation of spermatocytes. One month after DEX treatment the seminiferous tubules appeared highly proliferative, whereas the cohort of long spermatids was diminished. This could represent a block of meiosis. The DAZL-positive proliferating spermatocytes and spermatogonia disappeared completely after treatment with DXR, whether administered solely or with DEX. Absolute testicular recovery from DEX effect was observed at later time points (3 months and notably 6 months post treatment).

The striking phenomenon revealed in this study was the detrimental effect exerted by the co-administration of DEX and DXR: whereas DXR treatment resulted in marked testicular toxicity, manifested by obliteration of the unique morphology of the seminiferous tubules, with partial recovery in both sperm anatomy and functional parameters, the combination of DEX and DXR hampered histological recovery, resembling the Sertoli-cell-only pattern; and significantly reduced epididymal weight and sperm motility. Furthermore, fewer seminiferous tubules contained proliferating cells in testes of mice 1 month after receiving the combined DEX-DXR treatment than in testes of mice treated with DXR alone. The majority of the tubules in the testes of DXR-treated mice recovered and exhibited all types of germ cells, whereas most of the tubules in the testes of DEX-DXR treated mice exhibited Sertoli-cell-only pattern with no proliferating cells.

We can therefore conclude that despite alleviating the testicular oxidative stress induced by DXR, DEX exacerbates DXR-induced testicular toxicity, possibly via a direct effect on germ cells.

Chemotherapy-induced testicular toxicity may be one of the long-term effects of anti-cancer treatment, representing the 'cost of successful cure' and may be manifested by infertility and hypogonadism. Studies have shown that gonadal failure in young patients is associated with poor quality of life, decreased sexual functioning, and psychosocial distress related to infertility concerns (Schover et al. 2002, Zebrack et al. 2008). Multiinstitutional studies have addressed reproductive outcomes among survivors of childhood cancers and young adults who were treated with chemotherapy. Nevertheless, detailed information with regard to the gonadotoxic potential of different regimens is lacking. Our study was initially designed to employ the widely used DEX as a potential protectant, based upon its proved action as a cardioprotectant. Due to the detrimental effect of DEX on the testis in combination with DXR, further studies should be performed to investigate its mechanism of toxicity and its long-term effect. In the meantime, prudent selection of the young patients for DEX administration that are indeed at high risk of cardiotoxicity, may be recommended to avoid potential gonadotoxic effects in a larger population. Further clinical registry of long-term reproductive effects stratified upon various treatment protocols should be encouraged as well.

\section{Supplementary data}

This is linked to the online version of the paper at http://dx.doi. org/10.1530/REP-15-0129.

\section{Declaration of interest}

The authors declare that there is no conflict of interest that could be perceived as prejudicing the impartiality of the research reported.

\section{Funding}

This work was supported by a grant from the Israel Science Foundation (grant number 1816/13 to IBA).

\section{Author contribution statement}

M Levi, I Ben-Aharon, M Tzabari, R Shalgi developed the concept. I Ben-Aharon, R Shalgi and M Levi designed the experiments. I Ben-Aharon and $M$ Levi wrote the manuscript. $M$ Levi and M Tzabari carried out the experiments, data organization and statistical analyses. S M Stemmer participated in analyzing and discussing the results. R Shalgi conceived the study, participated in its design and coordination, helped drafting the manuscript and supervised the study. All authors read and approved the final manuscript.

\section{Acknowledgements}

The authors are grateful to the following people from Sackler Faculty of Medicine, Tel Aviv University: Ruth Kaplan-Kraicer, for her help in preparing the manuscript and Dr Mitelman Leonid, for his excellent assistance with the confocal microscopes.

\section{References}

Abraham SK \& Fränz J 1983 Induction of sister-chromatid exchanges by chemotherapeutic drugs in spermatogonia of mice: effects of procarbazine, adriamycin, cyclophosphamide and mitomycin C. Mutation Research 108 373-381. (doi:10.1016/0027-5107(83)90133-1)

Andoh T \& Ishida R 1998 Catalytic inhibitors of DNA topoisomerase II. Biochimica et Biophysica Acta 1400 155171. (doi:10.1016/S01674781(98)00133-X)

Ateşşahin A, Türk G, Karahan I, Yilmaz S, Ceribaşi AO \& Bulmuş O 2006 Lycopene prevents adriamycin-induced testicular toxicity in rats. Fertility and Sterility 85 1216-1222. (doi:10.1016/j.fertnstert.2005.11.035)

Au WW \& Hsu TC 1980 The genotoxic effects of adriamycin in somatic and germinal cells of the mouse. Mutation Research 79 351-361. (doi:10.1016/0165-1218(80)90160-3)

Bakshi RP, Galande S, Bali P, Dighe R \& Muniyappa K 2001 Developmental and hormonal regulation of type II DNA topoisomerase in rat testis. Journal of Molecular Endocrinology 26 193-206. (doi:10.1677/jme.0. 0260193) 
Bar-Joseph H, Ben-Aharon I, Tzabari M, Tsarfaty G, Stemmer SM \& Shalgi R 2011 In vivo bioimaging as a novel strategy to detect doxorubicin-induced damage to gonadal blood vessels. PLOS ONE 6 e23492. (doi:10.1371/journal.pone.0023492)

Bar-Shira Maymon B, Yogev L, Yavetz H, Lifschitz-Mercer B, Schreiber L, Kleiman SE, Botchan A, Hauser R \& Paz G 2003 Spermatogonial proliferation patterns in men with azoospermia of different etiologies. Fertility and Sterility 80 1175-1178. (doi:10.1016/S0015-0282(03) 02161-7)

Ben-Aharon I, Bar-Joseph H, Tzarfaty G, Kuchinsky L, Rizel S, Stemmer SM \& Shalgi R 2010 Doxorubicin-induced ovarian toxicity. Reproductive Biology and Endocrinology 8 20. (doi:10.1186/1477-7827-8-20)

Blanco-Rodríguez J \& Martínez-García C 1996 Spontaneous germ cell death in the testis of the adult rat takes the form of apoptosis: re-evaluation of cell types that exhibit the ability to die during spermatogenesis. Cell Proliferation 29 13-31. (doi:10.1046/j.13652184.1996.d01-5)

Bradford MM 1976 A rapid and sensitive method for the quantitation of microgram quantities of protein utilizing the principle of protein-dye binding. Analytical Biochemistry 72 248-254. (doi:10.1016/00032697(76)90527-3)

Brilhante O, Okada FK, Sasso-Cerri E, Stumpp T \& Miraglia SM 2012 Late morphofunctional alterations of the Sertoli cell caused by doxorubicin administered to prepubertal rats. Reproductive Biology and Endocrinology 10 79. (doi:10.1186/1477-7827-10-79)

Brinkworth MH, Weinbauer GF, Schlatt S \& Nieschlag E 1995 Identification of male germ cells undergoing apoptosis in adult rats. Journal of Reproduction and Fertility 105 25-33. (doi:10.1530/jrf.0.1050025)

Brougham MF, Kelnar CJ, Sharpe RM \& Wallace WH 2003 Male fertility following childhood cancer: current concepts and future therapies. Asian Journal of Andrology 5 325-337.

Chapman DL \& Wolgemuth DJ 1994 Regulation of M-phase promoting factor activity during development of mouse male germ cells. Developmental Biology 165 500-506. (doi:10.1006/dbio.1994.1270)

Cvetković RS \& Scott LJ 2005 Dexrazoxane: a review of its use for cardioprotection during anthracycline chemotherapy. Drugs 65 1005-1024. (doi:10.2165/00003495-200565070-00008)

Grauslund M, Thougaard AV, Füchtbauer A, Hofland KF, Hjorth PH, Jensen PB, Sehested M, Füchtbauer EM \& Jensen LH 2007 A mouse model for studying the interaction of bisdioxopiperazines with topoisomerase Ilain vivo. Molecular Pharmacology 72 1003-1014. (doi:10.1124/mol.107.036970)

Green DM, Kawashima T, Stovall M, Leisenring W, Sklar CA, Mertens AC, Donaldson SS, Byrne J \& Robison LL 2010 Fertility of male survivors of childhood cancer: a report from the Childhood Cancer Survivor Study. Journal of Clinical Oncology 28 332-339. (doi:10.1200/JCO.2009.24. 9037)

Horev-Azaria L, Eliav S, Izigov N, Pri-Chen S, Mirelman D, Miron T, Rabinkov A, Wilchek M, Jacob-Hirsch J, Amariglio N et al. 2009 Allicin up-regulates cellular glutathione level in vascular endothelial cells. European Journal of Nutrition 48 67-74. (doi:10.1007/s00394-008-0762-3)

Hou M, Chrysis D, Nurmio M, Parvinen M, Eksborg S, Söder O \& Jahnukainen K 2005 Doxorubicin induces apoptosis in germ line stem cells in the immature rat testis and amifostine cannot protect against this cytotoxicity. Cancer Research 65 9999-10005. (doi:10.1158/00085472.CAN-05-2004)

Jirkovský E, Lenčová-Popelová O, Hroch M, Adamcová M, Mazurová Y, Vávrová J, Mičuda S, Šimůnek T, Geršl V \& Štěrba M 2013 Early and delayed cardioprotective intervention with dexrazoxane each show different potential for prevention of chronic anthracycline cardiotoxicity in rabbits. Toxicology 311 191-204. (doi:10.1016/j.tox.2013.06.012)

Kamel D, Mackey ZB, Sjöblom T, Walter CA, McCarrey JR, Uitto L, Palosaari H, Lähdetie J, Tomkinson AE \& Syväoja JE 1997 Role of deoxyribonucleic acid polymerase epsilon in spermatogenesis in mice. Biology of Reproduction 57 1367-1374. (doi:10.1095/biolreprod57.6.1367)

Keizer HG, Pinedo HM, Schuurhuis GJ \& Joenje H 1990 Doxorubicin (adriamycin): a critical review of free radical-dependent mechanisms of cytotoxicity. Pharmacology \& Therapeutics 47 219-231. (doi:10.1016/ 0163-7258(90)90088-J)

Laberge RM \& Boissonneault G 2005 On the nature and origin of DNA strand breaks in elongating spermatids. Biology of Reproduction 73 289-296. (doi:10.1095/biolreprod.104.036939)
Lissbrant IF, Lissbrant E, Persson A, Damber JE \& Bergh A 2003 Endothelial cell proliferation in male reproductive organs of adult rat is high and regulated by testicular factors. Biology of Reproduction $\mathbf{6 8}$ 1107-1111. (doi:10.1095/biolreprod.102.008284)

Longhi A, Macchiagodena M, Vitali G \& Bacci G 2003 Fertility in male patients treated with neoadjuvant chemotherapy for osteosarcoma. Journal of Pediatric Hematology/Oncology 25 292-296. (doi:10.1097/ 00043426-200304000-00005)

Lowry OH, Rosebrough NJ, Farr AL \& Randall RJ 1951 Protein measurement with the folin phenol reagent. Journal of Biological Chemistry 193 265-275.

Lyu YL, Kerrigan JE, Lin CP, Azarova AM, Tsai YC, Ban Y \& Liu LF 2007 Topoisomerase II $\beta$ mediated DNA double-strand breaks: implications in doxorubicin cardiotoxicity and prevention by dexrazoxane. Cancer Research 67 8839-8846. (doi:10.1158/0008-5472.CAN-07-1649)

Masala A, Faedda R, Alagna S, Satta A, Chiarelli G, Rovasio PP, Ivaldi R, Taras MS, Lai E \& Bartoli E 1997 Use of testosterone to prevent cyclophosphamide-induced azoospermia. Annals of Internal Medicine 126 292-295. (doi:10.7326/0003-4819-126-4-19970215000005)

McCoard SA, Lunstra DD, Wise TH \& Ford JJ 2001 Specific staining of Sertoli cell nuclei and evaluation of Sertoli cell number and proliferative activity in Meishan and White Composite boars during the neonatal period. Biology of Reproduction 64 689-695. (doi:10.1095/biolreprod64.2.689)

Meistrich ML, van Beek ME, Liang JC, Johnson SL \& Lu J 1990 Low levels of chromosomal mutations in germ cells derived from doxorubicin-treated stem spermatogonia in the mouse. Cancer Research 50 370-374.

Oakberg EF 1957 Duration of spermatogenesis in the mouse. Nature $\mathbf{1 8 0}$ 1137-1138. (doi:10.1038/1801137a0)

Octavia Y, Tocchetti CG, Gabrielson KL, Janssens S, Crijns HJ \& Moens AL 2012 Doxorubicin-induced cardiomyopathy: from molecular mechanisms to therapeutic strategies. Journal of Molecular and Cellular Cardiology 52 1213-1225. (doi:10.1016/j.yjmcc.2012. 03.006)

Phillips BT, Gassei K \& Orwig KE 2010 Spermatogonial stem cell regulation and spermatogenesis. Philosophical Transactions of the Royal Society of London. Series B, Biological sciences 365 1663-1678. (doi:10.1098/ rstb.2010.0026)

Quiles JL, Huertas JR, Battino M, Mataix J \& Ramírez-Tortosa MC 2002 Antioxidant nutrients and adriamycin toxicity. Toxicology 180 79-95. (doi:10.1016/S0300-483X(02)00383-9)

Saunders PT, Turner JM, Ruggiu M, Taggart M, Burgoyne PS, Elliott D \& Cooke HJ 2003 Absence of mDazl produces a final block on germ cell development at meiosis. Reproduction 126 589-597. (doi:10.1530/rep. $0.1260589)$

Schover LR, Brey K, Lichtin A, Lipshultz LI \& Jeha S 2002 Knowledge and experience regarding cancer, infertility, and sperm banking in younger male survivors. Journal of Clinical Oncology 20 1880-1889. (doi:10.1200/JCO.2002.07.175)

Sepe DM, Ginsberg JP \& Balis FM 2010 Dexrazoxane as a cardioprotectant in children receiving anthracyclines. Oncologist 15 1220-1226. (doi:10.1634/theoncologist.2010-0162)

Shinoda K, Mitsumori K, Yasuhara K, Uneyama C, Onodera H, Hirose M \& Uehara M 1999 Doxorubicin induces male germ cell apoptosis in rats. Archives of Toxicology 73 274-281. (doi:10.1007/s002040050617)

Sikka SC 1996 Oxidative stress and role of antioxidants in normal and abnormal sperm function. Frontiers in Bioscience 1 e78-e86.

Steger K, Aleithe I, Behre H \& Bergmann M 1998 The proliferation of spermatogoniain normal and pathological human seminiferous epithelium: an immunohistochemical study using monoclonal antibodies against Ki-67 protein and proliferating cell nuclear antigen. Molecular Human Reproduction 4 227-233. (doi:10.1093/molehr/4.3.227)

Suominen JS, Linderborg J, Nikula H, Hakovirta H, Parvinen M \& Toppari J 2003 The effects of mono-2-ethylhexyl phathalate, adriamycin and $\mathrm{N}$-ethyl-N-nitrosourea on stage-specific apoptosis and DNA synthesis in the mouse spermatogenesis. Toxicology Letters 143 163-173. (doi:10.1016/S0378-4274(03)00170-X)

Tanigaki R, Sueoka K, Tajima H, Nakabayashi A, Sato K, Asada H, Kato S, Hosoi Y \& Yoshimura Y 2013 C-kit expression in spermatogonia damaged by doxorubicin exposure in mice. Journal of Obstetrics and Gynaecology Research 39 692-700. (doi:10.1111/j.1447-0756.2012.02006.x) 
Thomson AB, Campbell AJ, Irvine DC, Anderson RA, Kelnar CJ \& Wallace WH 2002 Semen quality and spermatozoal DNA integrity in survivors of childhood cancer: a case-control study. Lancet $\mathbf{3 6 0}$ 361-367. (doi:10.1016/S0140-6736(02)09606-X)

The Office of New Drugs in the Center for Drug Evaluation and Research (CDER) at the Food and Drug Administration USFDA. 2005 Guidance for Industry - Estimating the Maximum Safe Starting Dose in Initial Clinical Trials for Therapeutics in Adult Healthy Volunteers. U.S. Department of Health and Human Services Food and Drug Administration Center for Drug Evaluation and Research (CDER) July 2005. Pharmacology and Toxicology (http://www.fda.gov/ohrms/dockets/98fr/02d-0492-gdl0002.pdf)

Vejpongsa P \& Yeh ET 2014 Topoisomerase $2 \beta$ : a promising molecular target for primary prevention of anthracycline-induced cardiotoxicity. Clinical Pharmacology and Therapeutics 95 45-52. (doi:10.1038/clpt.2013.201)

Vendramini V, Sasso-Cerri E \& Miraglia SM 2010 Amifostine reduces the seminiferous epithelium damage in doxorubicin-treated prepubertal rats without improving the fertility status. Reproductive Biology and Endocrinology 8 3. (doi:10.1186/1477-7827-8-3)

Wallace WH 2011 Oncofertility and preservation of reproductive capacity in children and young adults. Cancer 117 2301-2310. (doi:10.1002/ cncr.26045)

Wang Y, Knudsen BR, Bjergbaek L, Westergaard O \& Andersen AH 1999 Stimulated activity of human topoisomerases $\| \alpha$ and $I \beta$ on RNA-containing substrates. Journal of Biological Chemistry 274 22839-22846. (doi:10.1074/jbc.274.32.22839)
Ward E, Desantis C, Robbins A, Kohler B \& Jemal A 2014 Childhood and adolescent cancer statistics, 2014. CA: A Cancer Journal for Clinicians 64 83-103. (doi:10.3322/caac.21219)

Wolf MB \& Baynes JW 2006 The anti-cancer drug, doxorubicin, causes oxidant stress-induced endothelial dysfunction. Biochimica et Biophysica Acta 1760 267-271. (doi:10.1016/j.bbagen.2005.10.012)

Yeh YC, Lai HC, Ting CT, Lee WL, Wang LC, Wang KY, Lai HC \& Liu TJ 2007 Protection by doxycycline against doxorubicin-induced oxidative stress and apoptosis in mouse testes. Biochemical Pharmacology 74 969-980. (doi:10.1016/j.bcp.2007.06.031)

Yeh YC, Liu TJ, Wang LC, Lee HW, Ting CT, Lee WL, Hung CJ, Wang KY, Lai HC \& Lai HC 2009 A standardized extract of Ginkgo biloba suppresses doxorubicin-induced oxidative stress and p53-mediated mitochondrial apoptosis in rat testes. British Journal of Pharmacology 156 48-61. (doi:10.1111/j.1476-5381.2008.00042.x)

Zebrack BJ, Yi J, Petersen L \& Ganz PA 2008 The impact of cancer and quality of life for long-term survivors. Psycho-Oncology 17 891-900. (doi:10.1002/pon.1300)

Received 22 March 2015

First decision 5 May 2015

Revised manuscript received 26 June 2015

Accepted 7 July 2015 